\title{
Notes on the vocalizations of Ashy Robin (Heteromyias albispecularis)
}

Peter Boesman

In the following we briefly analyze and compare voice of the different races of Ashy Robin (Heteromyias albispecularis). We also try to quantify the extent of any vocal differences using the criteria proposed by Tobias et al. (2010), as a support for taxonomic review. We have made use of sound recordings available on-line from Xeno Canto (XC).

Song of all races is a series of short notes at constant pitch, but race albispecularis has a more regular series of notes, unlike the more jerky uneven pace of song of other races:

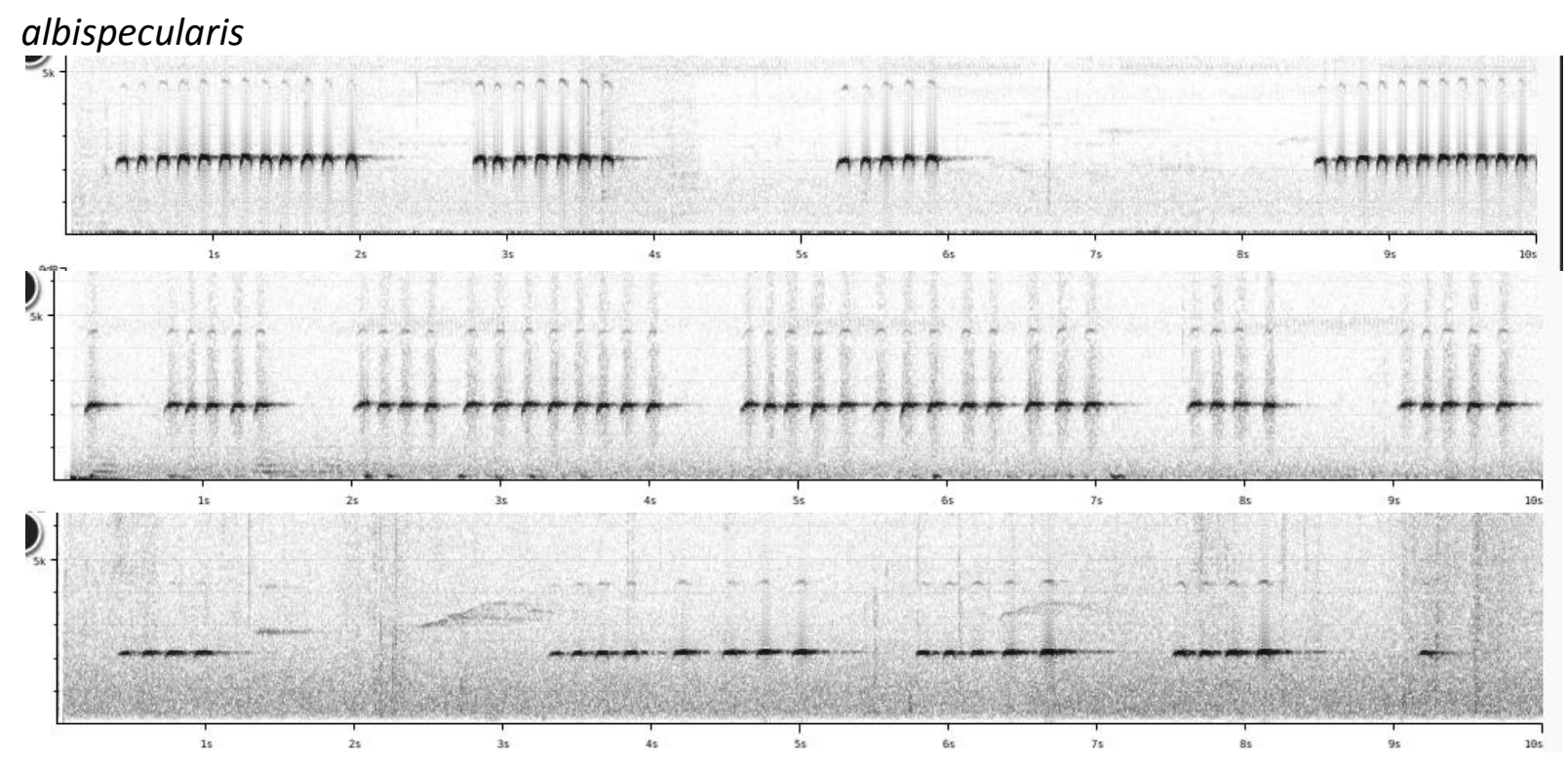

Other races

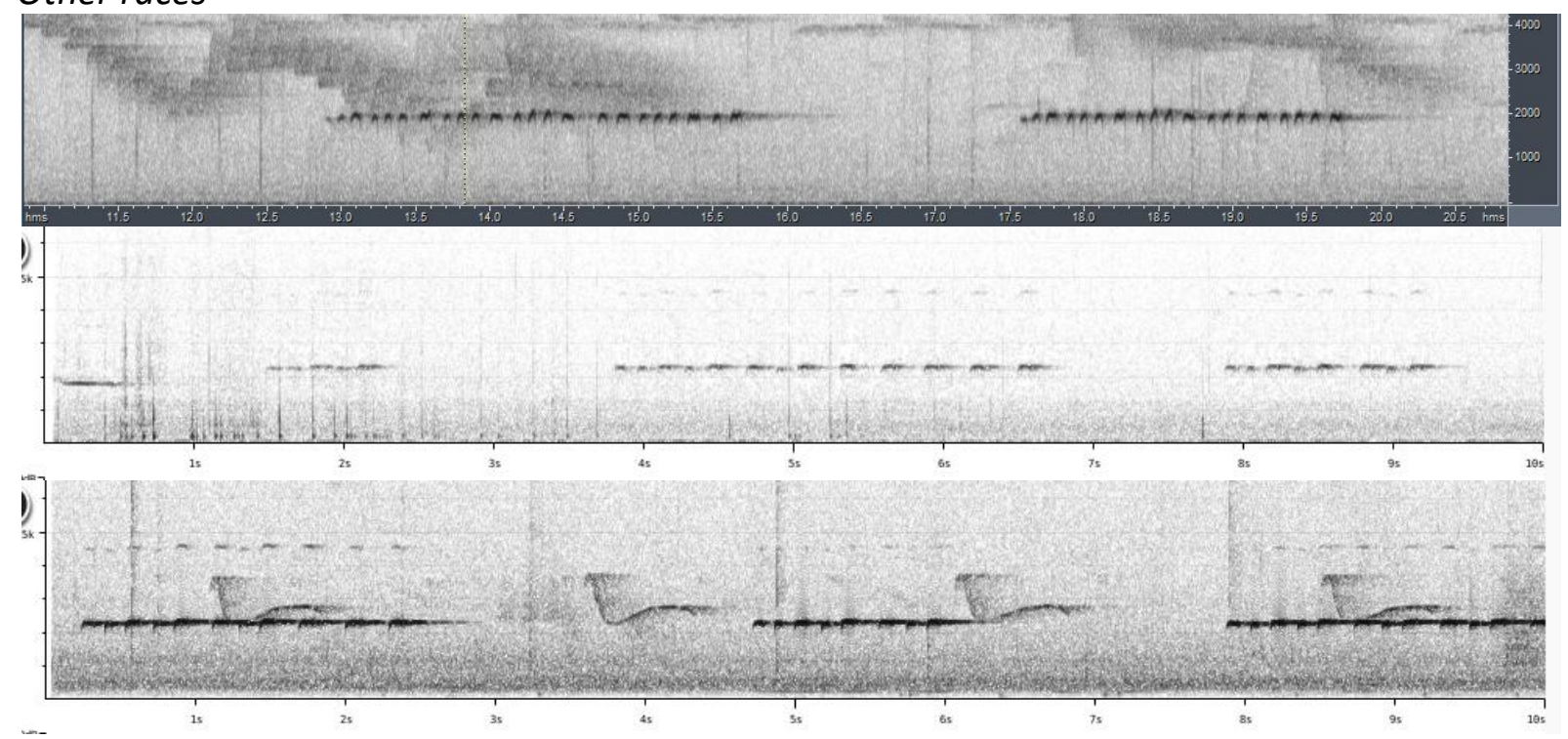



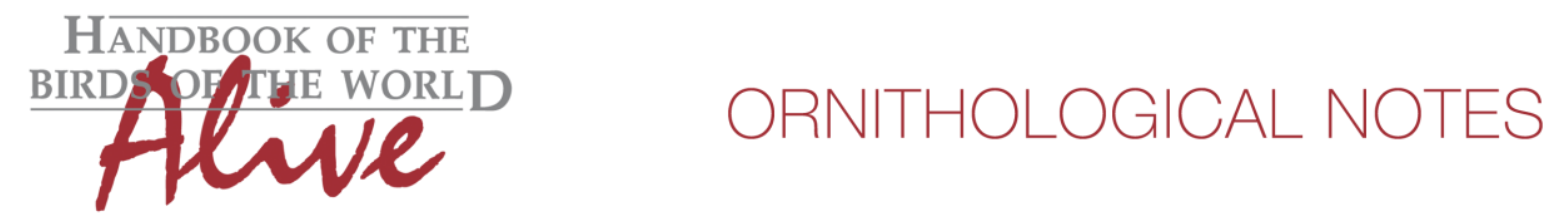

Other differences are the very stable amplitude of all notes which have about the same length in albispecularis, compared to the uneven amplitude and note length in other races. There is however some overlap, not every fragment can be safely identified. It is likely however that any longer recording would be identifiable.

For better appreciation, we reproduce the same sonograms with a more detailed time-scale (albispecularis top, other races bottom):

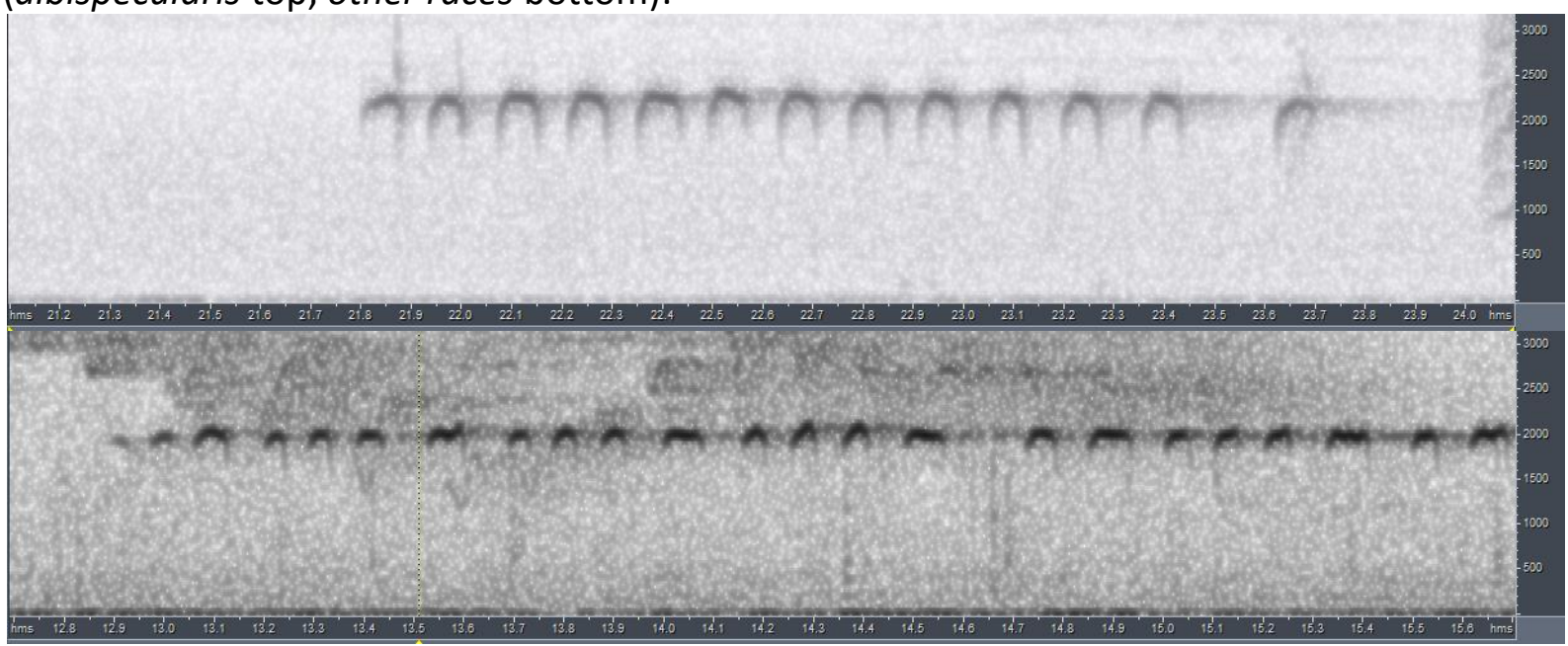

Vocal difference can thus be scored as follows:

albispecularis has a song consisting of repeated notes, which all have about the same length and shape (vs notes with different length and shape, score 2 ) and all at stable amplitude (score 2 ), and which are delivered at a steady pace ( $v$ s irregular and slightly faster in other races, score 2). When applying Tobias criteria, this would lead to a total vocal score of 4 .

This note was finalized on 2nd February 2016, using sound recordings available on-line at that moment. We would like to thank in particular the sound recordists who placed their recordings for this species on XC: Nick Athanas, Mike Catsis, Phil Gregory, Frank Lambert, Hans Matheve, John V Moore, Andrew Spencer, Bas Van Balen and Sam Woods.

\section{References}

Tobias, J.A., Seddon, N., Spottiswoode, C.N., Pilgrim, J.D., Fishpool, L.D.C. \& Collar, N.J. (2010). Quantitative criteria for species delimitation. Ibis 152(4): 724-746.

\section{Recommended citation}

Boesman, P. (2016). Notes on the vocalizations of Ashy Robin (Heteromyias albispecularis). HBW Alive Ornithological Note 215. In: Handbook of the Birds of the World Alive. Lynx Edicions, Barcelona. (retrieved from http://www.hbw.com/node/932173 on 6 September 2016). 